Session 2233

\title{
Expected Future Technology Direction for Small Electric Generator Sets
}

\author{
Herbert L. Hess \\ University of Idaho \\ Department of Electrical and Computer Engineering \\ Moscow, Idaho
}

\begin{abstract}
A summary of a recent study into the future of small, portable electric generation technologies. The changing character of the load is identified and a set of basic principles for design and analysis are developed. A number of candidate technologies are considered and evaluated. The effect of information technologies is considered, including real time control, operation and maintenance management, and policy development.
\end{abstract}

Introduction

Small generator sets for electric power in remote locations have an important place in the agriculture and tourism industries of the rural western US. They increase the ability to use the land cleanly, safely, and productively and to enjoy its recreational beauty. Therefore, manufacturers are making improvements to create cleaner, quieter, more reliable small generators that are easy to move and provide power on demand. Over the next two decades, a number of technological advances currently in the laboratory will appear on models in the field. Though underlying power generation technologies have received most of the publicity, it is the effect of information-based technologies that will most radically change this industry. This paper describes what advances technology should come to small portable electric generators in the next twenty years.

Character of the load

Knowing the nature of the load can be helpful in understanding the relative effectiveness of various technologies that may be considered for future mobile electric power production. Certain power generation technologies are better than others to supply certain loads.

Loads can be accurately characterized as "power on demand". Though loads are typically agricultural to recreational, their common thread is a degree of rapid response to demand. The power range typical for small, portable generators is 500 Watts to about $100 \mathrm{~kW}$. This range is chosen for practical reasons: a generator this size must be transported by vehicle, but is still completely self-contained. The load itself is typically one or more of the following: lighting, climate control, pumping a fluid, or electronics.

The following principles apply to the design of small, portable generators to supply these loads: a. A single basic design is preferable. Commonality simplifies and reduces the problems of maintenance, but supports a wide range of applications. Modularizes special capabilities.

Proceedings of the 2003 American Society for Engineering Education Annual Conference \& Exposition Copyright (C) 2003, American Society for Engineering Education 
Design is easily scalable. The market size is finite, so economies of scale must be obtained wherever possible.

b. Effectively produce power immediately upon placement. Once in operation, continue to produce electric power on demand even as the load may change.

c. Easily connected to a variety of loads.

d. Safe to operate.

e. Clean and friendly to a fragile environment. Minimum emissions and acoustic noise.

f. Mobile with weight and volume reductions vice existing technology.

g. Anticipates new technologies and can incorporate them into the design quickly.

h. Provides excellent fuel efficiency from highly reliable and maintainable equipment.

i. Incorporates information technology to enhance performance. Uses state-of-the-art sensors and prognostic/diagnostic capabilities.

j. Easy to install, operate, and maintain.

k. Affordable life cycle costs.

This environment presents big challenges for small portable electric power generators. They must produce power on demand for a range of loads from a single economical underlying basic design. They must meet a host of expectations, from safety and ease of use to affordable costs at every stage of its life cycle. In the next section, the various competing technologies are introduced and analyzed to determine which is most likely to provide portable electric power in the next couple decades.

Available technologies

Several technologies, whose physics has been known for quite awhile, provide a basis for generating portable electric power. Nonetheless, each technology is expected to advance significantly in the next twenty years. Some of these advancements are in the basic technology itself. However, information technologies hold the greatest promise for significant advancement of small, portable power generators. Most of the recent and expected improvements use information intelligently, from advanced real time control techniques to insightful methods of performance enhancement. This trend shows no sign of slackening. This paper addresses several technologies that appear to have a long-term future in small portable electric generation. Each has advantages for a certain set of conditions and applications. Following that discussion, the more global effect of information technologies is considered.[1]

Internal combustion engine

This is the incumbent technology. Most portable electric generators presently consist of a gasoline or diesel engine driving a wound-field rotating electric machine at a single speed. This is presently the dominant technology in terms of the performance drivers: low cost, portable, reliable, safe, quiet, and clean. Though improvements in other energy technologies get much of the publicity, the technology of the internal combustion engine is by no means standing still. In fact, the stream of innovations expected for the internal combustion engine in the next twenty years and beyond poses probably the most substantial problem for competing technologies.[2] The advent of the Hybrid Electric Vehicle (HEV) will further accelerate this sequence of improvements. The internal combustion engine dominates all applications in which it presently appears and will likely remain competitive for the foreseeable future.[3] 
Improvements in the internal combustion engine appear in a variety of areas. Improved materials will appear for the following purposes: greater strength, lighter weight, better heat management, better lubrication and wear, and more effective acoustic insulation. The relatively safe, efficient transfer of energy available from petroleum-based fuels contributes a great deal to the internal combustion engine's dominance. There is only one factor indicating that this may change in the next twenty years: In industry, the regulatory environment places improving emissions is a higher priority than other performance improvements.

A number of improvements expected in the next twenty years may be best described as advances in information-based control technology. Examples of these include the following: Variable valve lift and timing, programmed cylinder deactivation, variable response forced injection, variable compression ratio, homogeneous charge compression ignition, multistage direct injection, spark ignition of diesel fuel, and improved real time diagnostics and control. The HEV will likely use an internal combustion engine, consolidating the transportation and generation functions. In most cases, the HEV will be somewhat oversized for the expected generator loads, requiring advanced power management methods that are currently being developed in other industries, such as cellular communication, so the problem of light loads will likely be solved.

Because the internal combustion engine provides energy in a kinetic form, an electric machine must convert that energy to electrical form. In the rotating system, speed, frequency, and voltage are closely related. Power electronics can convert a wide range of variable frequency, variable voltage output to the fixed frequency, fixed voltage that the load requires. The technology to do this quite well has been known since the mid-1980s in the uninterruptible power supply (UPS) industry. Effective power electronics makes the permanent magnet generator dominant in this power range, taking advantage of its self-excitation, compactness, energy efficiency, and ruggedness, overcoming its wide voltage variations and sensitivity to faults.

\section{Turbine engine}

Though turbine engines have been available for many years, a turbine engine as a competitive means of mobile electric power generation is a relatively recent development. Within the last ten years, a few companies, primarily from the Western US and Japan, have developed a practical, fairly portable, electric turbine generator. The whole system uses readily available components. Advances in information-based control technology have been the basis for its success. High speed control technology closely regulates combustion in such a small turbine. It can operate near stoichiometric fuel-air ratios, improving its efficiency and emissions. Advanced signal processing provides real time control and responsive maintenance diagnostics. All turbine generators contain a host of diagnostics and additional datalogging for maintenance purposes.

As a prime mover for a rotating electric generator, a turbine has significant advantages. It has mechanical simplicity: only one moving part. A microturbine can run for days without attention and its total projected life that is six times that of a comparable internal combustion engine. Its high rotating speed gives it a great energy density. It has a nearly universal fuel capability. It is quieter than an internal combustion engine, but not as quiet as other competing technologies. Unfortunately, its tolerances are exacting and its materials are expensive. It does not respond as quickly to a load change as competing technologies. To overcome these disadvantages, additional equipment must be added, defeating much of its size and simplicity advantage. 
Research continues on several important issues. Scaling up and down appears to be quite possible in the power range at hand. Ruggedness is also being verified, but appears to be quite good. Because turbines are quite sensitive to small particles, changing the filter is the most common maintenance action and filter technology becomes important. Power electronics have become modularized, as expected. Energy storage to mitigate load variations, meaning batteries, is the largest part of a turbine's volume. Information technologies continue to advance in the turbine industry. Real-time control, on-line diagnostics, and wireless communication in support of the entire maintenance suite are already in beta testing.

The microturbine appears to be the one technology that will give the internal combustion engine serious competition. It is quieter, cleaner, and more reliable, can operate for days without attention, has a nearly universal fuel capability and has already incorporated a great deal of information technology into its operation and maintenance.

Fuel cell

Fuel cells offer clean, quiet power. Efficiency claims are routinely greater than $30 \%$, often far greater, particularly in cogeneration situations. Their output is a clean, direct current, free from harmonics and most power quality problems. Proton Exchange Membrane (PEM) fuel cells, the most appropriate technology for the power range at hand, have become packaged for easy handling and maintenance, lacking the corrosive constituents and high temperatures of their larger cousins. They even require only about half of the power electronics of their variable speed internal combustion engine and turbine competition.

There is little doubt that fuel cells already exist in the power range at hand. Several manufacturers sell hydrogen fuel cell stacks as OEM items. The problem is not the existence of a marketable product or inability to manufacture the hardware. Then why are fuel cells just a few years from success, as they have been for most of their two-century history? Fuel cells have not captured the small generator market because they face two diverging roads to success, each with a substantial roadblock.

Hydrogen is the fundamental fuel of the fuel cell. It can be packaged remotely and delivered to the fuel cell or it can be derived from other fuels at the fuel cell's location. These two options indicate the two roads to fuel cell success. Providing packaged hydrogen to a fuel cell yields clean, quiet, efficient operation in a fuel cell stack that already is commercially available. The problem is transportation and storage of hydrogen. This requires either high-pressure containers or the use of materials for storage, such as metal hydrides. Significant improvements in energy density and public perception of safety are necessary before such methods become practical. The astonishing cost of creating a safe and effective distribution network defeats hydrogen as a primary fuel when one considers the substantially lower cost of its competition: hydrocarbon fuels for rotating generators.

A second option is to develop appropriate reformer technology, deriving hydrogen on site from other fuels. Reformers are presently at various stages of development, but there is little doubt that a practical reformer for methanol and probably natural gas will be ready well before 2015 . Practical, portable, inexpensive reformers for other fuels, such gasoline, diesel fuel, or kerosene 
are unlikely to appear in the next twenty years. The military is the only major customer who wants such a reformer for electric power generation, but they lack the market to encourage the necessary research investment. Direct fuel cells, those that perform the reformer and fuel cell functions simultaneously, are too short-lived to be competitive.

Other common fuel cell problems may be grouped into the following categories: water management, responsiveness, ruggedness, materials, sensors and control technology, and cost. Water management has been solved, for the most part, but can still be a problem when starting in cold temperatures. Fuel cells are even less responsive than turbines, meaning that a great deal of energy storage will be required for adequate transient performance. How fuel cells stand up to the rugged life of a portable generator is unknown, but the initial indications are not good. The fuel cell requires more expensive materials and components, including sensors and control technology, than its competition. Keeping a fuel cell operating smoothly as a portable generator is far more complicated and expensive than keeping its competition operating to the same standard of performance. Further improvements in advanced information technology are needed just to bring the fuel cell to market, let alone to make it competitive. Consequently, fuel cells are more expensive and less practical than their competition and will likely remain so.

A correlation of all the recent press releases on fuel cells by companies, customers, and government agencies in an enlightening study. In 1998, nearly every press release announced deal-making and promises. Few announced products. Over the following years, occasionally a prototype appeared. By 2002, the prototypes and products were becoming more and more substantial and the time between prototype and product announcements was clearly becoming less and less. Product announcements are still a minority, but the trend is positive. How the automobile companies treat fuel cells may be the best available indicator. Automobile manufacturers made the decision in 2001 to invest above the billion dollar per year level.[4] They have committed to fuel cell ready production models by 2007 . They have substantial political and government support. There is little doubt that they have a market for a reasonably priced fuel cell. However, if the automobile companies fail, then they will give the fuel cell such a "black eye" that it will take decades to recover. One need look no further than their treatment of Stirling engines or all-electric vehicles to find an example.

Solar

In the West, there is abundant sunshine. Photovoltaics provide the promise of clean, quiet direct current free of harmonics and most power quality problems. They give reliable power on demand when sunlight is available and are easily scalable. Unfortunately, photovoltaics have problems with energy density, responsiveness, efficiency, portability, and perhaps ugliness.

Important improvements have appeared for several of these issues. Newer, lightweight, flexible panels have appeared recently. Efficiency is now approaching $15 \%$ for practical materials. Costs have decreased to about $\$ 5$ per watt. Further improvements are expected over then next twenty years. There is still a long way to go. At projected efficiencies and with reasonable improvement in materials, a 500-Watt system in the year 2015 will require about six square meters and weigh a little less than a ton with batteries to provide power to ITIC power quality recommendations.[9] For a class of intermittent loads, such as agricultural water pumping, solar is an excellent solution. The utilities now package trailers for farmers to leave in remote sites to

Proceedings of the 2003 American Society for Engineering Education Annual Conference \& Exposition Copyright (C) 2003, American Society for Engineering Education 
provide reliable water for livestock and irrigation. However, for the wider market, solar cells are not quite as practical as their competition. Projected rates of growth in the industry are moderate, probably about $5 \%$ annually for the next couple decades, lending financial market support to that perception of limited practicality.[2]

The same issues apply to wind generation. The energy source is different and the costs are somewhat less. (Wind generation is projected to cost 2 cents per kw-hr by 2015, quite competitive with other commercial generation.)[5] A wind system is even less portable. The same remote agricultural applications are appropriate and a niche cogeneration market for recreation appears, e.g., wind turbines for ski slopes and remote vacation homes.

Biomass is the second most common renewable energy resource in the US. It accounts for $38 \%$ of the electricity generated from renewable sources, second only to hydroelectric.[5] Applications include incineration of garbage and recycling of landfill gas. Ordinarily, fluidized bed technology provides an efficient means of extracting energy from fuel source with a low energy density. Portability is the obvious problem because biomass requires a comparatively large physical plant, about 15 cubic meters for a $20 \mathrm{~kW}$ operation for 48 hours. This does not scale down well.

Thermophotovoltaic (TPV) generator TPV generators use radiant energy from a burning fuel to drive a photovoltaic module. TPV has the advantages of silence and size. They have no moving parts, operate on a wide range of fuels, are comparable in size to a similarly rated fuel cell, and produce a great deal of heat. Their electrical output is clean, direct current, free from harmonics and most power quality problems.

Unfortunately, energy efficiency for TPV units is typically 3\% to $5 \%$. With improved materials and burner designs over the next decade or two, improvements to $12 \%$ seem possible, perhaps even $15 \%$. These units are difficult to scale beyond 500 Watts. Unless there is a niche application that uses the heat that they produce, then TPV generators are not yet competitive as a generation technology for the power range at hand.

The California Energy Commission has funded a creative solution to the problems of solar cells and TPV units: a 1.1MW "farm" of a host of photovoltaic units that perform as solar cells during the day and as TPV units at night.[6] These innovations produce niche markets that keep their base technologies alive, but normally fail to attract a wide spectrum of the applications.

Power technologies

There are a few other possibilities, such as radioisotope generation and external combustion. However, these are impractical for the Western market because no new nuclear generation, particularly of a portable variety, despite its reliability, would be politically tolerable in a Western state for the foreseeable future. External combustion systems are too heavy and slow to be practical. The most practical technologies appear to be the internal combustion engine and the microturbine. These technologies work best today. New information technologies will enhance them to a degree that other technologies will have difficulty keeping pace, let alone surpassing them. Appropriate fuels will be available in sufficient quantities for the next two decades and more. Other technologies should continue to be monitored. In the case of the fuel cell, the response of the automobile companies will be the best indicator. Energy harvesting, 
such as photovoltaics or wind systems, will fit into niche applications and may supplement other technologies.

Information technologies

Advances in information technology will transform small, portable electric power generation. These are the same technologies that the military uses to transform yesterday's soldier into tomorrow's Land Warrior. On a much grander scale, these technologies have transformed our entire society into an information-based culture.

There has been a growing propensity to address performance issues in technologies germane to small, portable electric power generation by intelligently and rapidly applying information technology to the problem. A fundamental level of technology can be added to the generator itself. These include advanced sensors and microprocessor-based real time control of equipment operation. The man-machine interface can also be improved with information technology: human factors for both efficient indication and command input, appropriate display technology for both on-site and remote interface to the operator, and on-line interactive maintenance diagnostics. Wireless communication of operation and maintenance information to those who repair the equipment will permit more effective dispatching of maintenance people, tools, and spare parts as well as better logistic and maintenance planning for the operator and for the repair shop. Taking this one step beyond the repair shop, information technologies based in the soft sciences will provide software to turn raw data into better policy decisions and innovations. Excellent information security is absolutely necessary for these innovations to become and remain effective. In the past, reliable, responsive electric power has been foundational to advances in communication, computation, control, and a host of other information-based technologies. The roles are becoming reversed or, more accurately, the functions are becoming more complementary.

As the preceding discussion of the various generation technologies shows, most of the recent advances in each technology are information based, primarily real-time control innovations due to fast signal processing. The internal combustion engine becomes more dominant; the turbine becomes competitive; the fuel cell becomes possible, etc. Information technology first interfaces directly to humans in the realm of status reports and maintenance management. These innovations apply in the same manner to every underlying power generation technology. Sensors for temperature, fuel consumption, intake and exhaust flows, pressure, speed of moving parts, voltages, currents, location, etc. Miniaturization and wireless communication are improving their effectiveness. Even sensorless methods are an important complement: they were intended to eliminate sensors, but are more effective when providing fault tolerance. Display technology has also improved dramatically. Displays have begun to appear on the generator, displays that provide the operator with a great deal of performance data plus maintenance diagnostics and instructions. These will become significantly better, more rugged, and easier to read in the next several years. There is also interface to external and remote equipment, such as the laptop computer displays that the railroads' repair technicians can now connect to their mobile power generation equipment. In fact, remote wireless communications now enable a railroad maintenance shop to receive diagnostics from an eastbound locomotive in Wyoming transmitted to the repair shop in Minneapolis.[7] When the train arrives, the proper 
people with the right parts and on-line repair manuals are waiting to meet it. These capabilities await remote power generation equipment.

Winnowing large amounts of operating and maintenance data to produce policy decisions in a recent capability of the soft side of information technology. Trends in maintenance, for example, can be picked up across a large number of customers when all repair shops have software that automatically reports maintenance data to a central point. Correlating such data and identifying trends is a task for advanced decision aids. In this way, the manufacturer can understand problems early and remedy design problems. Data for research and development can be gathered with less Hawthorne effect. Situation aware technologies provide tools to reduce the information overload that decision-makers in such environments often face. As we understand more about learning, cognitive processes, task analysis, and decision making, the software for policy development will become more useful. Wal-Mart's ability to develop and use such software is credited as the greatest single contribution to US productivity between 1995 and 2000.[8]

\section{Conclusions}

For small, portable electric power generators, the internal combustion engine will remain the dominant technology for the next two decades. Turbines will give it some competition, but fuel cells and other methods will meet niche applications at best. The most significant advances will occur as information technologies are applied to the electrical generation process. These include real-time control, human interface for monitoring and maintenance, and tools for policy determination.

\section{References}

[1] Hess, H., Front End Analysis of Mobile Electric Power Research and Development for the 2015-2025 Time Frame," US Army Communications-Electronics Command Technical Report, 31 July 2002, p. 27.

[2] Farooque, M. and H.C. Maru, "Fuel Cells - the Clean and Efficient Power Generators," Proceedings of the IEEE, Vol 89, No 12, December 2001, pp. 1819-1829.

[3] Lave, L., et.al., "Life Cycle Analysis of Alternative Automobile Fuel/Propulsion Technologies," Environmental Science Technology, Vol 34, No 17, 4 August 2000, pp. 3598-3604.

[4] Browning, L., "Projected Fuel Cell Use in California," Arthur D. Little Report for the California Energy Commission, P600-01-022F, October 2001, pp. 20-23.

[5] Bull, S., "Renewable Energy Today and Tomorrow," Proceedings of the IEEE, Vol 89, No 8, August 2001, p. 1216.

[6] California Energy Commission, "Public Energy Interest Research March 2001 Report," http://www.ccst.ucr.edu/energy/pr/b32.html, Appendix B3, page 2, March 2001, read 7 January 2003.

[7] Phillips, D., "Digital Railroad," Technology Review, March 2002, pp. 36-41.

[8] Strage, M., "Wal-Mart Trumps Moore's Law,” Technology Review March 2002, pp. 19-20.

[9] ITIC (CBEMA) Curve Application Note, Technical Committee 3, Information Technology Industry Council, Retrieved 3 March 2003 from http://www.itic.org/technical/ iticurv.pdf.

\section{HERBERT L. HESS}

Herb Hess received the PhD degree from the University of Wisconsin-Madison in 1993. He served on the faculty of the United States Military Academy from 1983-1988. In 1993, he joined the University of Idaho, where he is Associate Professor of Electrical Engineering. He received the Best Paper Overall Award for the 1999 ASEE Annual Conference. His interests are in device and circuit aspects of power electronic energy converters. 